\title{
Predicting Veracity from Linguistic Indicators
}

\author{
Judee K. Burgoon \\ Center for the Management of \\ Information, University of Arizona \\ Tucson, AZ 85721 \\ jburgoon@cmi.arizona.edu
}

Lauren Hamel

Department of Oncology

Wayne State University School of

$$
\text { Medicine }
$$

4100 John R St.

Detroit, MI 48021

Lauren.Hamel@karmonos.org

Tiantian Qin

Department of Statistics

Purdue University

West Lafayette, IN 47906

tqin@purdue.edu 


\begin{abstract}
Both laboratory and field experiments have confirmed significant linguistic differences between truthful and deceptive discourse.. The current investigation focused on whether indicators of truth or deception are context-independent or are influenced by two context factors: motivation and modality. A 2 (veracity: truthful/deceptive) by 2 (incentives: high/low) by 3 (modality: FtF/audio/text) factorial experiment revealed that linguistic indicators are significantly related to veracity but results are highly sensitive to contextual factors.
\end{abstract}

Keywords-deception, veracity, linguistics, motivation, modality

\title{
I. INTRODUCTION
}

A well-established finding in the literature on deception detection is that human judges are only slightly better than chance accuracy when telling lies from truths (Aamodt \& Custer, 2006; Hartwig \& Bond, 2011). Yet, when making judgments along a rating scale, humans reliably differentiate truthful from deceptive messages (Bond \& DePaulo, 2006). One reason people may be sensitive to shades of difference in message veracity, despite their reluctance to label them as lies and truths, is that they detect differences in the language used in such utterances. And, just as people may be less able to state the rules of grammar than to recognize an ungrammatical utterance, they may rely on such linguistic differences in formulating their judgments despite being unable to explicitly articulate the indicators contributing to their judgments than their implicit knowledge warrants.

In the practitioner worlds of forensics and law enforcement, several tools that have been developed for ferreting out truthful from deceptive statements--the Scientific Content Analysis (SCAN) technique (Driscoll, 1994), Statement Validity Analysis (SVA) (Undeutsch, 1989), Criteria-Based Content Analysis (CBCA) (Steller \& G. Köhnken, 1989; Vrij, 2005)] and Reality Monitoring (Johnson \& Raye, 1981)--incorporate features such as pronoun use, verb tense, amount of detail, and verbatim recollections. Scientific evidence from both laboratory and field experiments has confirmed that truthful and deceptive discourse differ linguistically (Burgoon \& Qin, 2006; Fuller, Biros, Burgoon, \& Nunamaker [10][16]. Yet such features have not emerged as significant predictors in recent meta-analyses and summaries [4], [17]-[19], partly because some summaries predated the accelerating empirical attention to linguistic features, partly because the number of studies has been insufficient to warrant their inclusion, and partly because moderators have produced such variability in findings that their utility as reliable indicators has been questioned. For example, DePaulo et al. [17] included only nine linguistic indicators in their meta-analysis and two — response length and self-references — were highly 
variable. Buller and colleagues [20]-[21] established that linguistic features differed across different forms of deceit such as fabrications, concealments and equivocations.

Clearly, it would make the task of predicting whether an utterance or text segment is deceptive much simpler if indicators remained stable across contextual features such as topic genres, speaker motivation and modality for message transmission. In the case of nonverbal behavior, there has been a longstanding, if misplaced, belief that many indicators of deceit are universal and therefore context-independent (see, e.g., [22]; but for a counterpoint, see [23]). In the case of linguistic features, the mix of past findings points to the likelihood of significant moderator variables that are accounting for the inconsistencies across tests of linguistic indicators. It is this issue of possible moderators and the contextdependence or -independence of linguistic cues that the current investigation addresses.

Specifically, we consider if any classes of indicators transcend context, and whether moderators that are centrally important in criminal justice, forensic interviewing and deception detection contexts alter the linguistic patterns that are exhibited. Two moderators we consider are motivation and modality. Zhou et al. [16] and Burgoon and Qin [10] showed that linguistic indicators are highly dynamic across the course of an interview. Factors that might produce variability, apart from temporal considerations per se (e.g., acclimating to an interview task), are the degree to which a sender is motivated to put forward a favorable impression, and the modality in which communication takes place. Before taking up these factors, we present a brief description of what we mean by linguistic indicators and what features fall into each class.

\section{LINGUISTIC CATEGORIES AND INDICATORS}

By linguistics we mean lexical and syntactic features of language that are content-independent, that is, the actual semantic content of a segment of text or discourse is excluded, but meta-content features such as sensory details can be counted through the use of dictionaries. It is possible, for example, to measure how many terms refer to sight, sound, touch and so forth without knowing the specific sights, sounds and touches being described. Linguistic features can be extracted from written text or from transcribed oral discourse. Although much of the impetus for analyzing such features automatically has been their application to text-based communication such as emails, they are also applicable to spoken language.

The features we examined are ones that can be automatically identified from text. Most of the analysis utilized Agent99 Analyzer (A99A) [16], a software tool built upon the open-source General Architecture for Text Engineering (GATE) [24]. GATE is a Java-based, object-oriented architecture and development environment for analyzing, processing, or generating natural language. GATE comes with a shallow parser that decomposes text into sentences and words, a part-of-speech tagger, and capacity to compute a 
variety of counts and calculations [25]. A99A incorporated several additional linguistic-based algorithms, to which we added features that duplicated measures from the Grammatik tool in WordPerfect and the Whissell [26] dictionary, which includes over 7000 words with pre-assigned, empirically derived values along continua of pleasantness, imagery, and activation. The current set of linguistic classes and their associated indicators were taken from Zhou et al. [27], who had proposed a regrouping of features from the preceding Zhou et al. [16] experiment. The categories and sample operationalizations are described in Table 1.

TABLE I. LINGUISTIC CLASSES AND INDICATORS

\begin{tabular}{|c|c|}
\hline \multicolumn{2}{|c|}{ Linguistic Categories and Operationalizations of Indicators } \\
\hline Quantity & $\begin{array}{l}\text { Refers to the length of an utterance, expressed at the lowest } \\
\text { level in terms of morphemes and at the highest levels in } \\
\text { terms of entire utterances or turns at talk. }\end{array}$ \\
\hline \multicolumn{2}{|c|}{$\begin{array}{l}\text { 1. Syllables (morphemes and affixes) } \\
\text { 2. Verbs (words that characteristically are the grammatical center of a } \\
\text { predicate and express an act, occurrence, or mode of being) }\end{array}$} \\
\hline Complexity & $\begin{array}{l}\text { The degree to which a lexical item has few or many } \\
\text { syllables (lexical complexity) or a sentence has few or } \\
\text { many phrases and clauses (syntactic complexity) }\end{array}$ \\
\hline \multicolumn{2}{|c|}{$\begin{array}{l}\text { 1. Big words (\# of words with } 6 \text { or more characters) } \\
\text { 2. Readability (indices, e.g., Flesh-Kincaid or SMOG index) that measure } \\
\text { reading grade level or difficulty of comprehending a segment of text) }\end{array}$} \\
\hline Diversity & $\begin{array}{l}\text { Degree to which a segment of text uses many unique } \\
\text { words and phrases relative to the total number of words } \\
\text { or phrases in it }\end{array}$ \\
\hline \multicolumn{2}{|c|}{$\begin{array}{l}\text { 1. Lexical diversity (total \# of different words divided by total \# of words, } \\
\text { i.e., percentage of unique words in all words) }\end{array}$} \\
\hline Specificity & $\begin{array}{l}\text { Degree to which a segment of text is concrete and } \\
\text { specific or abstract }\end{array}$ \\
\hline $\begin{array}{l}\text { 1. Sensory } \\
\text { sensation } \\
\text { 2. Expressi } \\
\text { of adject }\end{array}$ & $\begin{array}{l}\text { tails (sensory experiences such as sounds, smells, physical } \\
\text { and visual details) } \\
y \text { (a measure of vividness, quantified as the relationship of \# } \\
\text { es + \# of adverbs divided by \# of nouns+ \# of verbs) }\end{array}$ \\
\hline Uncertainty & $\begin{array}{l}\text { Degree to which words or constructions introduce } \\
\text { ambiguity in meaning }\end{array}$ \\
\hline $\begin{array}{l}\text { 1. Modal ve } \\
\text { character }\end{array}$ & $\begin{array}{l}\text { s (auxiliary verbs like would, should, could that are } \\
\text { tically used with a verb of predication) }\end{array}$ \\
\hline Verbal & Language that expresses and creates psychological \\
\hline
\end{tabular}




\begin{tabular}{|c|c|}
\hline \multirow{2}{*}{\multicolumn{2}{|c|}{$\begin{array}{l}\text { Nonimmediacy distance } \\
\text { 1. Passive voice (form of a verb used when the subject is being acted upon } \\
\text { rather than doing something) }\end{array}$}} \\
\hline & \\
\hline Personalization & $\begin{array}{l}\text { Personalization: pronoun use that increases the } \\
\text { specificity of reference to self and others }\end{array}$ \\
\hline \multicolumn{2}{|c|}{$\begin{array}{l}\text { 1. Self-reference (first-person singular pronouns: I, me, my) } \\
\text { 2. Second person reference (you-references) }\end{array}$} \\
\hline Affect & $\begin{array}{l}\text { Words and expressions that convey the subjective } \\
\text { aspect of an emotion apart from bodily changes }\end{array}$ \\
\hline \multicolumn{2}{|c|}{$\begin{array}{l}\text { 1. Affect ratio (number of affect-laden words from a dictionary of affect } \\
\text { terms relative to total number of words) } \\
\text { 2. Pleasantness (positive or negative feelings associated with a term, based } \\
\text { on pre-scaled dictionary of terms) }\end{array}$} \\
\hline Activation & $\begin{array}{l}\text { Degree of dynamism expressed by emotional terms, } \\
\text { based on pre-scaled dictionary of terms }\end{array}$ \\
\hline Informality & Degree of adherence to formal, standard language forms \\
\hline \multicolumn{2}{|c|}{ 1. Typographical errors (\# of errors in written text) } \\
\hline $\begin{array}{l}\text { Cognitive } \\
\text { Processes }\end{array}$ & $\begin{array}{l}\text { Terms describing the respondent's thinking process } \\
\text { (e.g., "thought," "surmised") }\end{array}$ \\
\hline $\begin{array}{l}\text { Cognitive } \\
\text { Difficulty }\end{array}$ & Degree of nonfluencies in a segment of text \\
\hline $\begin{array}{l}\text { 1. Filled pause } \\
\text { that do not } \mathrm{d}\end{array}$ & $\begin{array}{l}\text { um, er, ah, you know, and similar nonlexical expressions } \\
\text { upt the flow of speech and substitute for a silent pause) }\end{array}$ \\
\hline
\end{tabular}

These indicators were all calculated on interview data taken from a mock theft experiment. In preview, participants either did or did not commit a theft of a wallet from a classroom, then all were interviewed about the theft and other topics (favorite class, work experience) by a trained interviewer. All interviewees were encouraged to claim innocence, producing truthful responding by innocent participants and deceptive responding by guilty respondents. To manipulate motivation, half the interviewees were given additional incentives in advance to be judged as credible and innocent of the theft. Interviews were either conducted face-to-face, over an audio channel, or via text chat.

\section{Moderators of DeCEPTION DeteCtion With Linguistic INDiCATORS}

\section{A. Motivation}

A first likely moderator is motivation. In the deception literature, degree of sender motivation has long been considered a major influence on both sender displays and receiver detection accuracy [3], [28]-[31]. A significant dispute among scholars has been whether the majority of extant literature, which is based on mundane, low-stakes lies, is generalizable to circumstances with significant jeopardy or adverse consequences if caught [17]-[32], [33]. Certainly 
motivation should exert more influence on performance under high- than low-stakes circumstances, yet even low-stakes situations have shown motivation effects on deception displays and their detection.

Also in dispute is whether motivation facilitates or impairs performance. DePaulo and Kirkendol [28] advanced the motivation impairment hypothesis which argues that motivated lies will be more transparent when judges have access only to nonverbal information but less transparent when they have access to verbal information. The implication is that motivation impairs nonverbal performance but improves verbal performance. Their research did not examine behavior itself, but Burgoon and Floyd [30] investigated several operationalizations of motivation for their effects on performance and concluded that motivation had positive effects on many aspects of both nonverbal and verbal behavior. Verbal performance was measured with information management composites of verdicality/personalism and completeness/directness/-clarity rather than with linguistic features. Recent research by Hancock et al. [34] found that highly motivated liars interacting in an instant-messaging medium (verbal only) were the most successful in deceiving their partners but they did not examine performance itself. A next logical step in the progression of linguistic indicators of deceit is thus to consider whether motivation moderates their use.

We contend, first, because higher motivation by definition represents a state of heightened readiness to act, it should be manifested through indicators of elevated arousal, activation and expressiveness. Regardless of veracity, motivated communicators may become more voluble (measured as quantity), may use more language scaled as high in imagery and activation, and may exhibit more verbal expressivity. Following principles of social facilitation, greater motivation should stimulate communicators to perform well those overlearned aspects of language that people typically "run off" without much forethought, including utterances that are relatively more complex, diverse, and specific. That, is their utterances should run toward bigger words rather than simple vocabulary, complex and compound sentences rather than simple constructions, varied rather than redundant word choice, and more rather than sparser sensory details. Motivated communicators also are likely to be more conscious of their self-presentation and to attempt to put their best face forward by appearing pleasant and friendly. These predictions regarding motivation should pertain to both truthful and deceptive responding: Motivation exerts a main effect on linguistic performance regardless of communicator veracity (HI).

Where motivation may interact with veracity to exert an ordinal impact on language is on those aspects of message production that are subject to impairment by excessive cognitive or emotional taxation. Comparatively, motivation may have a felicitous effect on those linguistic elements that communicators are best able and most likely to control and are therefore least easily degraded by cognitive or emotional overload. Speculatively, motivated deceivers should be able to produce lengthy messages that are complex, diverse, vivid and personalized and that may intentionally include more hedging language. Motivated deceivers may be less likely to monitor or control fluency and language reflective of 
negative affect or uncertainty. Thus we predict that motivation interacts with veracity to affect the quantity, complexity, diversity, personalism, vividness, fluency, affect and uncertainty of verbal communication (H2). 


\section{B. Modality}

It is well-known that people speak differently than they write, and synchronous communication such as chat differs from asynchronous communication such as emails, the former being far more informal, cryptic and studded with abbreviations than the latter, so modality in itself is bound to produce differences in the language that is used. Less obvious is whether modality should interact with sender veracity to produce differential patterns of features. To the extent that deceivers are strategic in their communication and take advantage of the potentials of a medium to present themselves in the most credible light, it may be that several features of deceptive language vary as a function of modality. For example, deceivers in face-to-face interaction must create messages on the fly and may focus more on their nonverbal presentation but also utilize receiver feedback to guide their message production, taking note when receivers seem to be accepting what they are saying and elaborating only when it appears that the receiver is not convinced by what they are saying. By contrast, deceivers in written mode have more opportunity to edit their messages before transmitting and to focus exclusively on what they are saying. Audio communication spares deceivers concerns with their visual self-presentation but they must also produce messages in a timely fashion without benefit of nonverbal feedback from the receiver. Thus, we speculate that modality may interact with veracity to affect linguistic features: Modality interacts with veracity to moderate linguistic patterns during interaction (H3).

\section{METHOD}

\section{A. Sample}

Participants $(N=186)$ were recruited from a multi-sectioned, introductory-level communication class for a study investigating "the ability of people to deceive others and escape detection." They received extra credit for participation and the chance to earn a monetary bonus if successful at convincing an interviewer of their innocence and credibility. Participants who confessed and those who failed to complete all measures were not included in the final sample. Among completions, 120 were female and 66 were male; 77\% were Caucasian, 13\% were African-American and 10\% were Hispanic/Latino, Pacific Islander, or another ethnicity; mean age was $19.6($ range $=18-31)$.

\section{B. Experimental Design and Procedures}

The experimental design was a 2 (veracity: truthful/deceptive) by 2 (incentives: high/low) by 3 (modality: FtF/audio/text) factorial, with participants assigned randomly to conditions. Those assigned to the deception condition were instructed to commit a mock theft of a wallet from their classroom and then to lie when interviewed about the theft immediately after class. 
Thieves had the wallet on their person during the interview. Those assigned to the truthful condition were instructed to be in class on certain days, alerted that a theft might take place, and instructed to be completely truthful during the interview immediately after class.

One of the problems surrounding testing of motivation is that often it has only been inferred rather than manipulated or measured directly, producing empirical findings fraught with inconsistencies and contradictions [29], [30]. Given that we define motivation as an internal drive an individual possesses, we chose to operationalize it through individual self-report. To instigate differential degrees of motivation, we followed methods common in past research that couples extrinsic rewards such as money with ego-based appeals meant to activate intrinsic motivation [17], [31], [35]-[36]. Those in the high incentive condition were told that, in addition to course credit, they could earn $\$ 10$ if the interviewer evaluated them as truthful and $\$ 50$ if they were the most successful at being evaluated as truthful. Those in the low incentive condition were told merely to convince the interviewer that they did not take the wallet and were reminded that regardless of how successful they were, they would receive course credit. After the interview, they became eligible for the same monetary rewards as those in the high motivation condition.

Interviews took place under one of three modalities. In the text condition, interviewer and interviewee were placed in separate rooms equipped with wireless notebook computers and conducted the interview using Microsoft NetMeeting's chat facility. In the audio condition, interviewer and interviewee were placed in the same separate rooms but communicated via handsets. In the face-to-face condition, interviewer and interviewee were located in the same room and the interview was video recorded for later transcription.

Upon reporting to the research site, interviewees completed a social skills pretest and a written statement following procedures common to criminal investigations. They were then interviewed by one of three trained interviewers who followed a Behavioral Analysis Interview (BAI) format that is taught to criminal investigators. After background questions related to high school and recent employment, the interview moved to the theft. Interviewees were asked if they committed the theft, to describe their activities on the day in question, to speculate about who might be responsible for the theft, what should be done to punish the perpetrator, and so forth. Two interviewers were trained by the third, who is a certified trainer in interviewing and interrogation. A pilot test provided extensive practice and feedback. All interviewers followed the same script and question sequence. Interviews averaged 10 minutes and were followed by a post-interview questionnaire and debriefing. 


\section{Dependent Measures}

Video and audio recordings were first transcribed; text chats were retained in verbatim form, with interviewer turns removed. All transcripts were then segmented by turns at talk so that each question could be analyzed separately. All text segments were analyzed using A99A. Given space limitations, only the theft portion of the interview was analyzed.

\section{RESULTS}

A 2 (veracity: truth/deception) x 2 (motivation: high/low) x 3 (modality: FtF/audio/text) MANOVA was conducted on each linguistic category. Veracity exerted a main effect on (1) affect, (2) immediacy, (3) specificity, and (4) personalism. Affect had a multivariate effect, $F(5,157)=2.90, p=.016$, partial $\eta^{2}=.085$; but no significant univariates for individual indicators, although the means suggest deceivers used more affect-laden language. On immediacy, the multivariate effect, $F(6,156)=$ $3.43, p<.001$, partial $\eta^{2}=.116$, was accompanied by significant univariates on modal verbs and temporal immediacy. On specificity, $F(2,160)=3.65, p=.03$, partial $\eta^{2}=.044$, there were no significant univariates but an interaction with motivation. Personalism had only a significant univariate on "you" pronouns. Deceivers used more modal verbs, which would qualify as nonimmediate, but also more temporal immediacy. They also used more "you" pronouns. No other indicators showed main effects for veracity. Thus, no linguistic classes emerged as consistently associated with truth or deception.

\section{A. Motivation Effects}

$\mathrm{H} 1$ predicted that motivation exerts a main effect on linguistic features regardless of veracity, and $\mathrm{H} 2$ predicted an additional ordinal interaction with veracity on the quantity, complexity, diversity, personalism, vividness, fluency, affect and uncertainty of verbal communication. Consistent with H1, a significant main effect for motivation emerged on (1) quantity, $F(3,159)=3.20, p=.025$, partial $\eta^{2}=.057$ (univariate effects on words, verbs, sentences), (2) affect (univariate only on extreme positive pleasantness), and (3) immediacy (significant univariate effects only on modifier quantity, temporal immediacy). Regardless of veracity, high-motivated senders used more words, verbs, sentences, positive pleasantness, modifiers, and temporal immediacy. Motivation thus altered language use in and of itself.

Of greater interest are the interactions with veracity. Motivation by veracity interactions emerged on (1) diversity, $F(3,165)=2.75, p=.044$, partial $\eta^{2}=.048$ (univariate on redundancy), (2) specificity (near-significant multivariate effect, $F(2,164)=2.62, p=.076$, partial $\eta^{2}=.031$, with univariate interactions on specificity and sensory terms ratio), and (3) personalism (univariate only, on other references). Whereas under high motivation, truthful and deceptive senders did not 
differ on these features, low-motivation deceivers used less redundancy and other references and more sensory terms and specificity than truthtellers. Fig. 1 is illustrative.

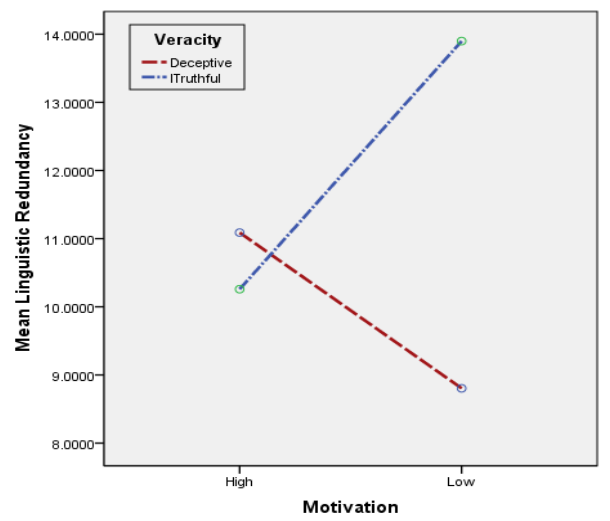

Figure 1. Effects of Veracity and Motivation on Linguistic Redundancy.

\section{B. Modality Effects}

H3 proposed that modality would moderate veracity effects. Main effects emerged on (1) quantity, $F(6,318)=4.48, p<$ .001 , partial $\eta^{2}=.078$ (words, verbs, sentences), (2) diversity, $F(6,318)=5.12, p<.001$, partial $\eta^{2}=.088$ (lexical diversity, redundancy, content word diversity), (3) complexity $F(6,318)=3.67, p=.002$, partial $\eta^{2}=.065$ (pausality, average sentence length, average word length), (4) immediacy, $F(4,330)=8.428, p<.001$, partial $\eta^{2}=.093$ (modifier quantity, spatial far ratio), and (5) personalism, $F(8,316)=3.72, p<.001$, partial $\eta^{2}=.086$ (first-person plural pronouns, total pronouns). Veracity interacted with modality only on affect, $F(10,314)=1.89, p=.046$, partial $\eta^{2}=.057$, with a significant univariate effect on the affect ratio. No other interactions emerged.

\section{DISCUSSION}

A central question when applying linguistic analysis to assess a person's veracity is whether indicators of truth or deception are context-independent or are influenced by factors such as motivation and modality. Current results indicate that while linguistic indicators produced numerous significant findings, results were highly sensitive to contextual factors. Even those classes of features that produced a main effect for veracity—affect, immediacy, specificity, and personalism—did not show a consistent pattern across conditions.

Affect, for example, was moderated by motivation, but no individual indicator had a strong enough impact on its own. Affect was also moderated by modality, confirming that how emotional people's language is depends on the combination of 
their truthfulness and the modality in force. Thus, affect patterns can only be considered as indicators of deceit when one knows the context.

Immediacy measures were affected by all three independent variables. Modal verbs distinguished truth from deception; temporal immediacy was related to both deception and motivation; modifiers were responsive to motivation or modality; and spatial distancing was affected by modality. Specificity measures also showed a main effect for veracity and an interaction with motivation (on specificity and sensory ratio). Whereas high- motivation respondents were similar linguistically regardless of their veracity, low-motivated deceivers were far more specific and detailed than low-motivated truthtellers. These patterns are contrary to the prediction that truthful utterances are more specific and that motivation facilitates deceivers looking truthful.

Personalism produced a main effect for veracity and interacted with motivation on "other" references. Low-motivated deceivers were less likely to mention third parties than were low-motivated truthtellers. Modality also affected personalism on first-person plural pronouns and total pronouns. These results indicate that different aspects of pronoun use are responsive to different factors.

Diversity was affected by a motivation by veracity interaction on redundancy. Modality also affected lexical diversity, redundancy, and content word diversity. Diversity differences may therefore be more due to modality than other factors.

These combined results point to the importance of precisely specifying the contextual conditions before making any predictions based solely on linguistic information. The high sensitivity of linguistic indicators represents a double-edged sword. With the correct specification of conditions, they could lead to precise assessment of veracity. But they also point to the necessity of knowing the context before making accurate predictions. The sparse knowledge of contextual moderators emphasizes the need for researchers to spell out the conditions under which different linguistic indicators are likely to emerge.

The current investigation also reinforces the importance of testing linguistic features under varying conditions so that greater precision can be attained in predictive models of linguistic usage. Because humans are less able to manage their linguistic selections on the fly, such indicators have great promise for deception detection, but they must be subjected to far more rigorous testing before firm conclusions can be drawn.

Future research should also validate the alignment of specific indicators with their purported classes If, for example, only one personalism feature is influenced by a given moderator, it raises the question of whether all pronoun forms serve the same function. The pronoun "I" could signal that a speaker is taking responsibility for a statement, or could signal nonimmediacy, 
as in "you and I" rather than "we." Moving to n-gram analyses and collocations that take into account collections of words in recurring expressions would advance understanding of what functions that utterances perform.

\section{CONCLUSION}

In conclusion, linguistic features clearly can signal the veracity of a speaker but those signals must be placed within, and adjusted according to, the context in which they occur. The degree of motivation that the speaker is likely to have, and the modality through which communication is taking place, are just two of the contextual features that must be factored into the interpretation of any linguistic signals.

\section{ACKNOWLEDGMENT}

This research was partially supported by funding from the U.S. Air Force Office of Scientific Research (Grant \#F49620-01-10394) and the Center for Identification Technology Research.

\section{REFERENCES}

[1] M. G. Aamodt and H. Custer, "Who can best catch a liar?: A meta-analysis of individual differences in detecting deception," The Forensic Examiner, vol. 15, pp. 7-11, 2006.

[2] C. F. Bond and B. M. DePaulo, "Individual differences in judging deception: accuracy and bias," Psychological Bulletin, vol. 134, pp. 477-492, 2008.

[3] C. F. Bond and B. M. DePaulo, "Accuracy of deception judgments," Personality and Social Psychology Review, vol. 10, pp. 214-234, 2006.

[4] M. Hartwig and C. F. Bond Jr, "Why do lie-catchers fail? A lens model meta-analysis of human lie judgments," Psychological Bulletin, vol. 137, pp. 643-659, 2011.

[5] L. N. Driscoll, "Validity assessment of written statements from suspects in criminal investigations using the scan technique," Police Studies, vol. 17, pp. 77-88, 1994.

[6] U. Undeutsch, "The development of Statement Validity Analysis," in Credibility Assessment, U. Undeutsch, Ed., The Netherlands: Kluwer, Dordrecht, 1989, pp. 101-121.

[7] M. Steller and G. Köhnken, "Criteria-based content analysis," in Psychological Methods in Criminal Investigation and Evidence., D. C. Raskin, Ed., New York: Springer Verlag, 1989, pp. 217-245.

[8] A. Vrij, "Criteria-Based Content Analysis: A Qualitative Review of the First 37 Studies.," Psychology, Public Policy, and Law, vol. 11, pp. 3-41, 2005. 
[9] M. K. Johnson and C. L. Raye, "Reality monitoring," Psychological Review, vol. 88, pp. 67-85, 1981.

[10] J. K. Burgoon and T. Qin, "The Dynamic Nature of Deceptive Verbal Communication," Journal of Language and Social Psychology, vol. 25, pp. 76-96, 2006.

[11] C. M. Fuller, D. P. Biros, J. K. Burgoon, and J. F. Nunamaker, "An examination and validation of linguistic constructs for studying high-stakes deception," Group Decision and Negotiation, Forthcoming.

[12] J. T. Hancock, L. E. Curry, S. Goorha, and M. Woodworth, "On lying and being lied to: A linguistic analysis of deception in computer-mediated communication," Discourse Processes, vol. 45, pp. 1-23, 2007.

[13] M. L. Newman, J. W. Pennebaker, D. S. Berry, and J. M. Richards, "Lying words: Predicting deception from linguistic styles," Personality and Social Psychology Bulletin, vol. 29, pp. 665-675, 2003.

[14] S. Porter and J. C. Yuille, "The language of deceit: An investigation of the verbal clues to deception in the interrogation context," Law and Human Behavior, vol. 20, pp. 443-458, 1996.

[15] S. L. Sporer, "The less travelled road to truth: verbal cues in deception detection in accounts of fabricated and selfexperienced events," Applied Cognitive Psychology, vol. 11, pp. 373-397, 1997.

[16] L. Zhou, J. K. Burgoon, J. F. Nunamaker, and D. Twitchell, "Automating linguistics-based cues for detecting deception in text-based asynchronous computer-mediated communications," Group Decision and Negotiation, vol. 13, pp. 81-106, 2004.

[17] B. M. DePaulo, J. J. Lindsay, B. E. Malone, L. Muhlenbruck, K. Charlton, and H. Cooper, "Cues to deception," Psychological Bulletin, vol. 129, pp. 74-118, 2003.

[18] A. Vrij, Detecting Lies and Deceit: The Psychology of Lying and the Implications for Professional Practice. New York: John Wiley \& Sons, 2000.

[19] A. Vrij, Detecting Lies and deceit: Pitfalls and Opportunities. Chichester, England: Wiley, 2008.

[20] D. B. Buller, J. K. Burgoon, A. Buslig, and J. Roiger, "Interpersonal deception: VIII. Nonverbal and verbal correlates of equivocation from the Bavelas et al. (1990) research," Journal of Language and Social Psychology, vol. 13, pp. 396-417, 1994.

[21] D. B. Buller, J. K. Burgoon, A. Buslig, and J. Roiger, "Testing interpersonal deception theory: The language of interpersonal deception," Communication Theory, vol. 6, pp. 268-289, 1996.

[22] M. G. Frank and P. Ekman, "The ability to detect deceit generalizes across different types of high-stake lies," Journal of Personality and Social Psychology, vol. 72, pp. 1429-1439, 1997. 
[23] J. Burgoon and D. B. Buller, "Interpersonal deception theory," in Engaging Theories in Interpersonal Communication: Multiple Perspectives, L. A. Baxter and D. O. Braithwaite, Eds., Los Angeles, CA: Sage, 2008, pp. 227-239.

[24] H. Cunningham, "GATE, a general architecture for text engineering," Computers and the Humanities, vol. 36, pp. 223$254,2002$.

[25] H. Cunningham, D. Maynard, K. Bontcheva, V. Tablan, C. Ursu, M. Dimitrov, M. Dowman, N. Aswani, and I. Roberts, "Developing Language Processing Components with GATE Version 3 (a User Guide)," 2005.

[26] C. M. Whissell, "The dictionary of affect in language," in Emotion: Theory, Research, and Experience. vol. 4, R. Plutchik, Ed., New York: Academic Press, 1989, pp. 113-131.

[27] L. Zhou, D. P. Twitchell, T. Qin, J. K. Burgoon, and J. F. Nunamaker Jr, "Toward the automatic prediction of deceptionan empirical comparison of classification methods," Journal of Management Information Systems, vol. 20, pp. 139-166, 2004.

[28] B. M. DePaulo and S. E. Kirkendol, "The motivational impairment effect in the communication of deception," in Credibility Assessment, J. Yuille, Ed., Deurne, Belguim: Kluwer, 1989, pp. 51-70.

[29] J. K. Burgoon, "The future of motivated deception and its detection," in Communication Yearbook 29, P. Kalbfleisch, Ed., Mahway, NJ: Erlbaum, 2005, pp. 49-95.

[30] J. K. Burgoon and K. Floyd, "Testing for the motivation impairment effect during deceptive and truthful interaction," Western Journal of Communication, vol. 64, pp. 243-267, 2000.

[31] M. Zuckerman and R. E. Driver, "Telling lies: Verbal and nonverbal correlates of deception," in Nonverbal Communication: An Integrated Perspective, A. W. Siegman and S. Feldstein, Eds., Hillsdale, NJ: Erlbaum, 1985, pp. 129-147.

[32] M. G. Frank and T. H. Feeley, "To catch a liar: Challenges for research in lie detection training," Journal of Applied Communication Research, vol. 31, pp. 58-75, 2003.

[33] A. Vrij and S. Mann, "Telling and detecting lies in a high-stake situation: the case of a convicted murderer," Applied Cognitive Psychology, vol. 15, pp. 187-203, 2001.

[34] J. T. Hancock, M. T. Woodworth, and S. Goorha, "See no evil: The effect of communication medium and motivation on deception detection," Group Decision and Negotiation, vol. 19, pp. 327-343, 2010.

[35] B. M. DePaulo, D. A. Kashy, S. E. Kirkendol, M. M. Wyer, and J. A. Epstein, "Lying in everyday life," Journal of Personality and Social Psychology, vol. 70, pp. 979-995, 1996. 
[36] B. M. DePaulo, K. Lanier, and T. Davis, "Detecting the deceit of the motivated liar," Journal of Personality and Social Psychology, vol. 45, pp. 1096 -1103, 1983. 
